\title{
Long-term efficacy and withdrawal of octreotide LAR in acromegaly patients, a prospective single centre study with 4 years follow up
}

Zelija Velija-Asimi+, Azra Burekovic+, Kemal Dizdarevic*

\section{+Clinic for Endocrinology and Diabetes, *Clinic for Neurosurgery, University Clinical}

Centre of Sarajevo, Bosnia and Herzegovina

\section{Objective}

The aim of this single centre prospective open trial was to evaluate the long-term efficacy of octreotide LAR in acromegaly patients and possibility of withdrawal of this therapy.

\section{Methods}

In total 17 patients with acromegaly diagnosed at Endocrinology Clinic in Sarajevo, somatostatin sensitive (10 females and 6 males, age range 37-65 years, 6 patients with microadenoma and 10 patients with macroadenoma) were treated with octreotide LAR. Follow-up period was 4 years (2009-2014). Ten patients were treated with surgical and octreotide treatment. One patient was treated with surgical, octreotide and gamma-knife treatment and six patients were treated only with octreotide LAR. The concentration of human Growth Hormone (hGH) and Insulin-Like Growth Factor I (IGF-1) were evaluated before treatment and every 6 months during follow-up period of 4 years, while magnetic resonance imaging (MRI) was taken before the treatment and every year during follow-up period. Thirteen patients received octreotide $30 \mathrm{mg} / 28$ days, two patient received $20 \mathrm{mg}$ and other two $60 \mathrm{mg} / 28$ days. Statistical data analysis includes basic statistics, descriptive statistics and nonparametric statistics (Friedman, Wilcoxon signed ranks test and Mann-Whitney U-test). Statistical significance was set as $p<$ 0.05. Copy and paste your text content here, adjusting the font size to fit.

Keywords: acromegaly, human growth hormone, insulin-like growth factor I, octreotide, pituitary adenoma

zelijav@gmail.com

\section{Results}

Table 1. The level of HGH, IGF-1 and size of pituitary adenomas during 48 months follow-up period of Sandostatin LAR treatment \begin{tabular}{l|l|l|l|l} 
Follow-up & $n$ & $\mathrm{HGH}(\mathrm{ng} / \mathrm{ml})$ & IGF-1 $(\mathrm{ng} / \mathrm{ml})$ & Size of adenoma $(\mathrm{mm})$
\end{tabular}

\begin{tabular}{|c|c|c|c|c|}
\hline 0 & 10 & 50,87 & 777 & 9,57 \\
\hline 6 months & 10 & $1,61(a)^{* * *}$ & $305,90(a)^{\star * *}$ & \\
\hline 12 months & 10 & $1,85(a)^{* * *}$ & $256,99(a)^{\star \star *}$ & $8(b)^{* *}$ \\
\hline 24 months & 17 & $1,61(a)^{* * *}$ & $305,90(a)^{* * *}$ & 5 (b) ** \\
\hline 36 months & 16 & $2,11(a)^{* * *}$ & $337,33(a)^{* * *}$ & 7,2 (b)** \\
\hline 48 months & 11 & $2,0(a)^{* \star *}$ & $276(a)^{\star \star \star}$ & $6(b)^{\star *}$ \\
\hline
\end{tabular}

a - Friedman test; $\mathrm{b}$ - Wilcoxon Signed Ranks Test

${ }^{\star} p<0.05 ;{ }^{* \star} p<0.01 ;{ }^{* \star *} p<0.005$

During the first year of treatment 10 patients were included. In the second year a further seven patients were involved. At one patient treatment was successful discontinued without subsequent recurrence during follow-up. After 2 years, at another 2 patients treatment was off because well-controlled acromegaly, one patient was died due to co-morbidities and at one another patients treatment was off due to kidney cancer. After 3 years of treatment one of patient must be subjected to gamma-knife treatment followed by continued treatment with $30 \mathrm{mg}$ of octreotide LAR and at one patient the dose was increased up to $60 \mathrm{mg}$. During the fourth year of follow-up, the treatment was successful discontinued at another one patient, so currently we followed total of 11 patients; 8 of them used therapy for 4 years and 3 of them used therapy for 3 years. During follow-up period octreotide LAR treatment significantly reduced $\mathrm{GH}(50.87 \pm 10.56$ vs $2 \pm 0.36 \mathrm{ng} / \mathrm{ml}, \mathrm{p}<0,005)$, IGF-1 $(777.66 \pm 118.40$ vs $276 \pm 80.54 \mathrm{ng} / \mathrm{ml}, \mathrm{p}<0,005)$ and adenoma size (from $9,6$ to $6 \mathrm{~mm}$; $\mathrm{p}<0,01)$. After therapy, a $\mathrm{GH}$ decrease to less than $2.5 \mathrm{ng} / \mathrm{ml}$ was achieved in $82 \%$ of cases; tumor size decrease was achieved in $60 \%$ while normalization of IGF-1 was achieved in $91 \%$ of the patients, respectively. At 12-24 months of follow-up, $23,5 \%$ of somatostatin sensitive acromegaly patients had withdrawn treatment, without recurrence.

\section{Conclusion}

Our findings demonstrated that octreotide LAR treatment is very effective in decrease of GH, IGF-1 and tumor size and their withdrawal, though rare, is possible in well-selected acromegalic patients treated for at least 2 years and considered optimally controlled in hormonal and neuroradiological terms.

\section{References}

Bandgar TR, Sarathi V, Shivane V, Bansode N, Menon PS, Shah NS. The value of an acute octreotide

suppression test in predicting response to long-term somatostatin analogue therapy in patients with acromegaly. J Postgrad Med. 2010 Jan-Mar;56(1):7-11.

Mattar P1, Alves Martins MR, Abucham J. Short- and long-term efficacy of combined cabergoline and octreotide treatment in controlling igf-I levels in acromegaly. Neuroendocrinology. 2010;92(2):120-7. 